\title{
Bendability and failure mechanisms of dual phase steel under air-bending at elevated temperatures
}

\author{
Natthasak Pornputsiri and Kannachai Kanlayasiri \\ Industrial Engineering Department, Faculty of Engineering, King Mongkut's Institute of Technology Ladkrabang, Bangkok, Thailand
}

\begin{abstract}
In this study, process parameters such as the bending angle and bending temperature of the metal sheets for pure bending of advanced high strength steel sheet DP980 were investigated using the air-bending method. This investigation focused on bendability and failure mechanisms. Experimental studies were carried out with various bending temperatures and the bending angle parameters to identify effect on springback angle, initial crack, and the evolution of the microstructure. Prior to testing, the DP steel sheets were heattreated at different temperatures (room temperature, $200{ }^{\circ} \mathrm{C}, 400{ }^{\circ} \mathrm{C}$, and $600{ }^{\circ} \mathrm{C}$ ) with a heating rate of $2{ }^{\circ} \mathrm{C} / \mathrm{S}$ and 5 minutes of holding time in an electric furnace. As a result of the experiments performed at different temperature values and bending angle values, it was determined that an increase in the bending angle reduces the size of the springback angle. It was also determined that an increase in air-bending-temperature reduces the amount of springback. Air-bending-temperature also affected the microstructure evolution and slowed the cracking of the bent surface.
\end{abstract}

\section{Introduction}

High strength steel, dual-phase (DP) steels type, have been commonly used in the motor manufacturing sector due to their high strength and formability, which makes them ideal for body construction and for use in the chassis [1]. The typical characteristics of DP steels, in terms of mechanical properties, include relatively low-yield strength, high-strain hardening, and continuous yielding behavior. Due to the relatively high-hardening rate of DP steels, a reasonable combination of formability and strength is provided [2]. These strong DP steels earned their name on account of the two phases from which they are composed; a ferrite matrix in combination with a martensitic phase. The benefits to the manufacturer include good formability along with increased strength, thereby allowing lighter cars and trucks to be built while offering an environmental advantage due to the lower cost offered by reducing the overall weight. The only drawback is that such steels can fail unexpectedly during bending by even the smallest radius, and the bending surface will frequently indicate signs of failure below the forming limit strain. One of the problems that needs to be solved is the springback issue [3].

Bendability is an indicator that shows the extent of formability for a sheet metal sample. One important manufacturing technique is air-bending, whereby the sheet metal components are produced using pure bending stress and severe forming. Therefore, it is necessary to fully understand the bendability properties of sheet metals in order to produce high-quality components. The sheet metal bending process for high-strength steel has extensive industrial applications, but it is difficult to complete the forming or bending process at room temperature due to the significant degree of deformation involved, as well as the high-flow stresses that affect the materials [4,5]. If the temperature is increased for the forming process, the flow stresses are lowered, residual stresses are also reduced, and deformation becomes easier, hence improving formability [6,7]. The lower flow stresses and heightened formability make it possible to achieve greater stretching, and permits deeper drawing in creating the final product [8]. Sheet metal bending at elevated temperatures that are below recrystallization temperature is considered warm forming. Materials can be formed into complex shapes without much difficulty at this temperature. While high temperature air-bending has not yet found effective commercial use, it is likely that it will become much more important in the future as the technique develops.

Good bendability is absolutely vital when making metal components which take complex forms. Therefore, it is important to develop more effective ways for AHSS to perform in industrial applications. Ability of the bending is could be evaluated as the lowest ratio of the inside bending radius ( $r$ ) to the sheet thickness $(t)$ that the sheet metal can accept without the manifestation of surface defects during bending to an angle of $90^{\circ}$ in pure bending [9]. Generally, when the sheet metal stronger is affected to decreasing of the bending ability. The damaging effect of stretched inclusions is well known, especially in advanced high strength steel (AHSS), on mechanical properties and bendability in conventional structural steels.

While the use of high temperature metal forming processes has not yet become widespread in industrial

* Corresponding author: kkkannac@kmitl.ac.th 
applications, it is expected that this will change. Therefore, one study that investigated the formability of pure titanium and titanium alloy at high temperatures is of particular interest, primarily because its findings present the effects of temperature when applied with highstrength metals [10]. However, studies involving highstrength steels are rather limited, meaning there is a gap that must be addressed because the applications are potentially valuable. The required temperatures for the formation of steel sheets are particularly high. The problems this presents may be responsible for the fact that few experiments have been conducted to date.

This research seeks to carry out an investigation of the effect of bending temperature on bendability and the damage mechanism in dual phase steel sheets (DP980), which would be examined with air-bending tests conducted at varying temperatures (room temperature to $600{ }^{\circ} \mathrm{C}$ ) in order to assess the suitability and limitations of the technique along with the results for springback angle, microstructure evolution, and failure mechanisms by optical microscope (OM), scanning electron microscope (SEM), and crystal structure by XRD.

\section{Experimental Procedures}

\subsection{Materials}

This research experimented with AHSS sheets of $1 \mathrm{~mm}$ thickness. For the dual phase steel (DP980) sheets used in this study, Table 1 tabulates their tensile mechanical properties, which were obtained on the Zwick universal testing machine according to ASTM E $8 \mathrm{M}$ at room temperature. The microstructures of the DP steel sheets were investigated via 50X Optical Microscope (OM), scanning electron microscopy (SEM), while the XRD measurements of the DPS microstructures were also investigated. Specimens of each heat treatment were metallographically prepared with a final polishing step of $0.1 \mu \mathrm{m}$. The macro-scale microstructure $(\mathrm{OM})$ and SEM study was made after etching with $2 \%$ Nital using the Optical Microscope (OLYMPUS, BX $60 \mathrm{M}$ ) and JEOL JSM-6510 LV FRG-SEM (field emission gun scanning electron microscope) working at $15 \mathrm{kV}$. The characterized microstructure of each heat treatment before the bending is shown in Fig. 1, where the ferrite $(\alpha)$ appears as light brown and the martensite $\left(\alpha^{\prime}\right)$ as a whitish color.

Table 1. Mechanical properties at room temperature

\begin{tabular}{|c|c|c|c|}
\hline Material & Ys (MPa) & UTS (MPa) & TE (\%) \\
\hline DP980 & 740 & 1020 & 16 \\
\hline
\end{tabular}

\subsection{Mechanical conformation tests}

Figure 2 illustrates the pure-bending, plane-strain experimental setup at different deformation temperatures, which was used to investigate the bendability and failure mechanisms of the DP980 steel sheets using three-point air-bending.

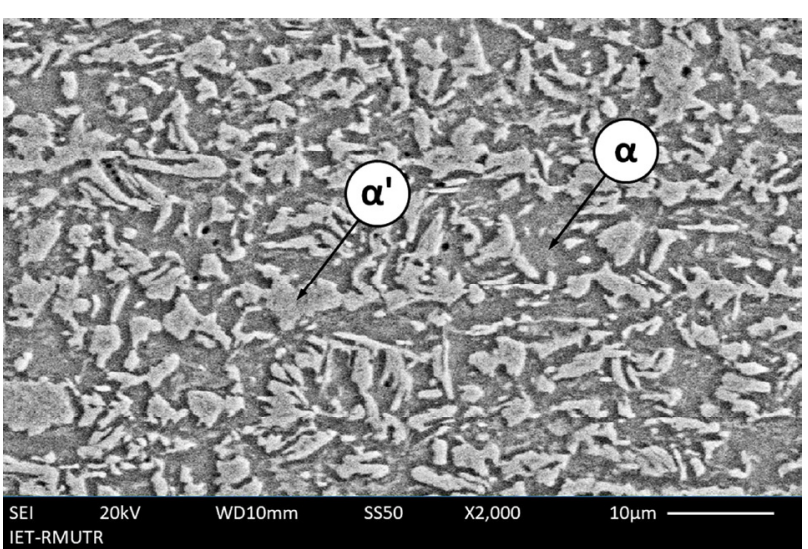

Fig 1. Microstructure of dual phase steel (DP980) observed via SEM image after $2 \%$ Nital etching

During experimentation, the specimen is subjected to a punch with a cylindrical body. The experiment was devised in accordance with the ISO 7438:2010 standard. The punch $\left(R_{p}\right)$ and roller $\left(R_{d}\right)$ radii were $0.25 \mathrm{~mm}$ and $10 \mathrm{~mm}$, respectively. The metal sheets were $12 \mathrm{~mm}$ in width (b), 30mm in length (1), and $1.0 \mathrm{~mm}$ in thickness (t). In the operation, the punch pressed downward while the support set remained stationary. The experiments were carried out by varying the bending angles in $15^{\circ}$ increments from $0^{\circ}$ to $75^{\circ}$. Uni-axial tensile tests were conducted with a Zwick Z20 universal testing machine at a constant bending speed of $60 \mathrm{~mm} / \mathrm{min}$.

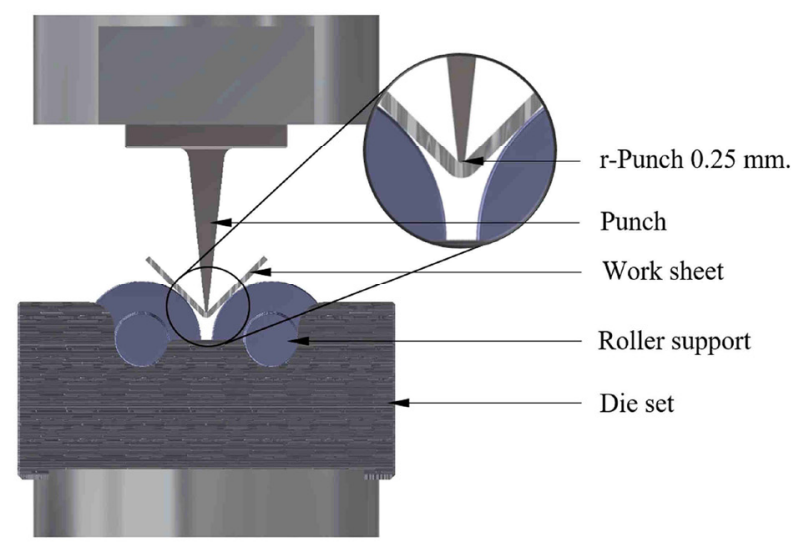

Fig 2. Air-bending tool ISO 7438:2010 standard

The tests were completed at varying temperatures including room temperature $(\mathrm{RT}), 200^{\circ} \mathrm{C}, 400^{\circ} \mathrm{C}$, and $600^{\circ} \mathrm{C}$ and without lubrication. Regulation of the temperature was accomplished through the use of a thermostatic chamber with sensitivity of $\pm 2{ }^{\circ} \mathrm{C}$ under warm and hot conditions. A thermocouple was set up at the position of the specimen, where the temperature was controlled precisely. The test pattern is shown in Fig. 3. First, the specimen was heated to the target temperature at a heat increase rate of $2{ }^{\circ} \mathrm{C} / \mathrm{s}$ using a thermostatic chamber, after which it was soaked for 5 min to assure complete austenitization [7]. The item being tested was then bent to accomplish the target bending angle utilizing the punch stroke and subsequently cooled in the air to room temperature. 


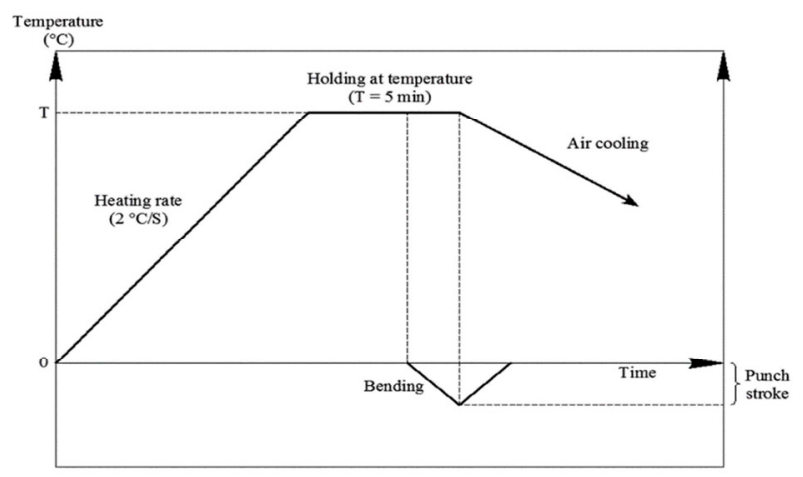

Fig 3. Scheme of the elevated temperature air-bending test procedure, which consists of four main steps: heating, holding, air-bending to the testing level, and air-cooling.

\section{Results and Discussion}

\subsection{Springback}

In the sheet metal forming process, the product geometry must be within dimensional tolerances. However, dimensional errors due to springback occur following the plastic deformation, which is are known to be among the most important problems encountered in the sheet metal forming process [11].

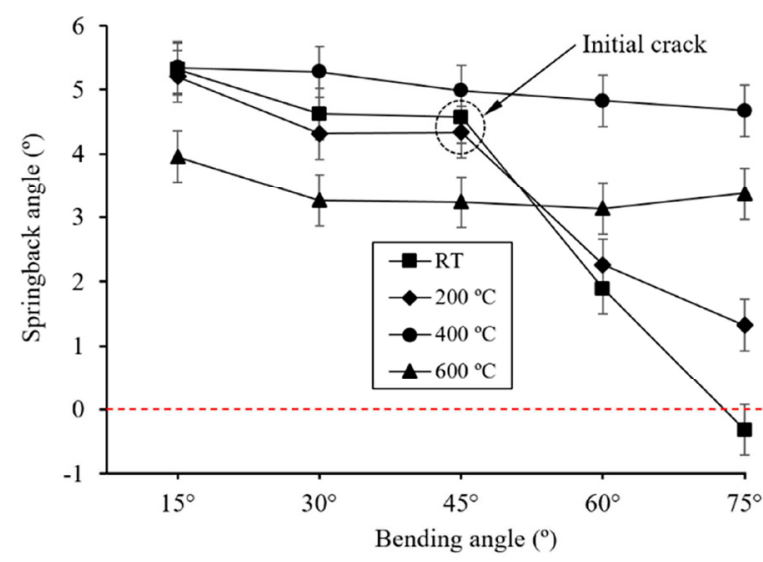

Fig 4. Bending angle - springback angle relationships

The springback results after bending in this study are shown in Fig. 4, which illustrates the influence of the bending angle on the springback angle. It was determined that an increase in bending angle decreased the springback angle at all temperatures. It was also clear that the angle of the springback increased for the temperature increase to $400{ }^{\circ} \mathrm{C}$, for bending at room temperature, and at 200 ${ }^{\circ} \mathrm{C}$. For bending at $45^{\circ}$, the springback decreased continuously, with the initial crack appearing on the convex bending surface, while the springback angle was likely to decrease as temperatures increased higher than $400{ }^{\circ} \mathrm{C}$. This was likely due to the yield strength and strain hardening decrease [12]. This leads to a reduction in the amount of springback occurring after the forming process [13]. In conclusion, springback is likely to decrease markedly for temperature increases above $400{ }^{\circ} \mathrm{C}$, while the microstructures of this steel are in the ferrite-pearlite phase at warm temperatures [7]. According to previous literature [14], recovery and recrystallization of partial ferrite occurs in specimens at this temperature. Thus, the bending strength and hardness becomes lower as the temperature rises higher than $400{ }^{\circ} \mathrm{C}$.

\subsection{Failure mechanisms}

The experimental process was continued up to the point when the convex surface began to show signs of fracture. These cracks tend to appear first in the central areas of the specimen because the plane strain is higher in these regions than at the edges, as confirmed by the ASM Handbooks (2000) [15].

Figure 5 shows the condition of the various bent specimens in differing bending states. The convex surface can be examined for cracks using 20X magnification. For the purposes of this study, minor wrinkling effects or an orange peel appearance is not taken to be a significant type of defect.

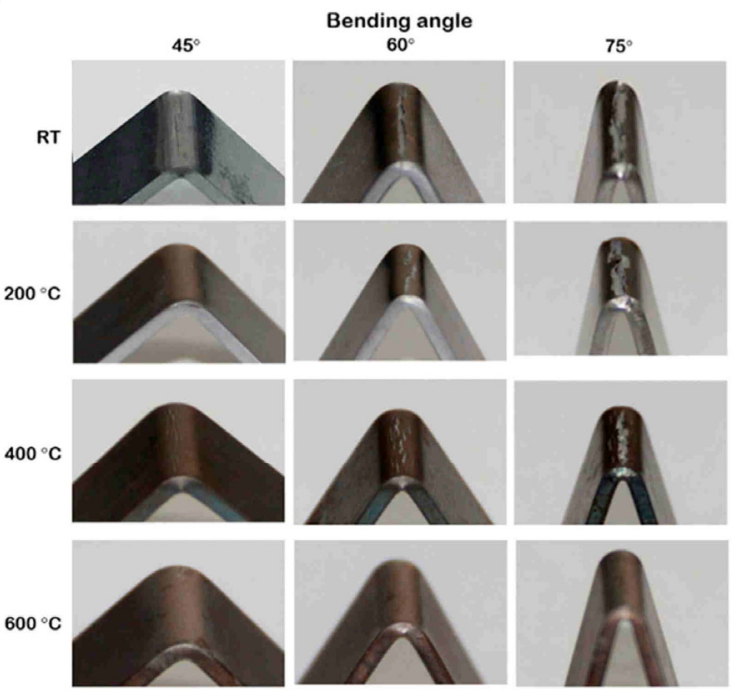

Fig 5. Various bent specimens shown at different temperatures and bending angles

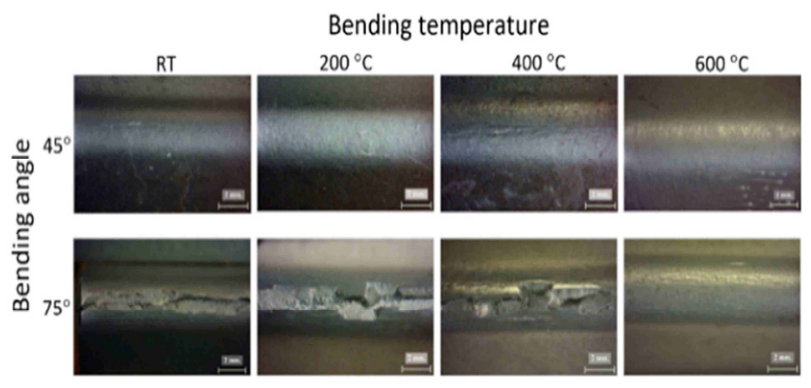

Fig 6. Development of surface undulations by extent of deformation

The different stages of a developing crack are shown in Fig. 6. The orange peel appearance becomes visible along with a wavy effect upon the surface. This undulation appears on the convex part of the bending region. As explained by Dao and Lie [16], the grooves that are formed cause the strain to be increased, leading to a lack of homogeneity in the plastic flow measured in micrometers. However, the defects are limited to narrow slip bands. 
When these slip bands intersect with a free surface, they can become the source of both intrusions and extrusions. Cracks tend to originate from intrusions, as would be expected on the basis of the findings related to bending, whereby the intruding undulations are where cracks are observed to start.

\subsection{Relationship between microstructures and crystal structures}

The microstructures of dual phase steel sheets produced by different temperatures show no changes in the ferrite phase following heat treatment that affects the austenite and ferrite regions. As the temperature rises, the fraction by volume of martensite declines.

The results in Fig. 7 reveal the usual DP980 XRD patterns as indicated by the XRD phase analysis performed at room temperature, $200{ }^{\circ} \mathrm{C}, 400{ }^{\circ} \mathrm{C}$, and 600 ${ }^{\circ} \mathrm{C}$ using $\mathrm{Cu} \mathrm{K} \alpha$ radiation. This technique offers accuracy of around $5 \%$, while a step of $2 \Theta$ occurs from 40 to 100 .

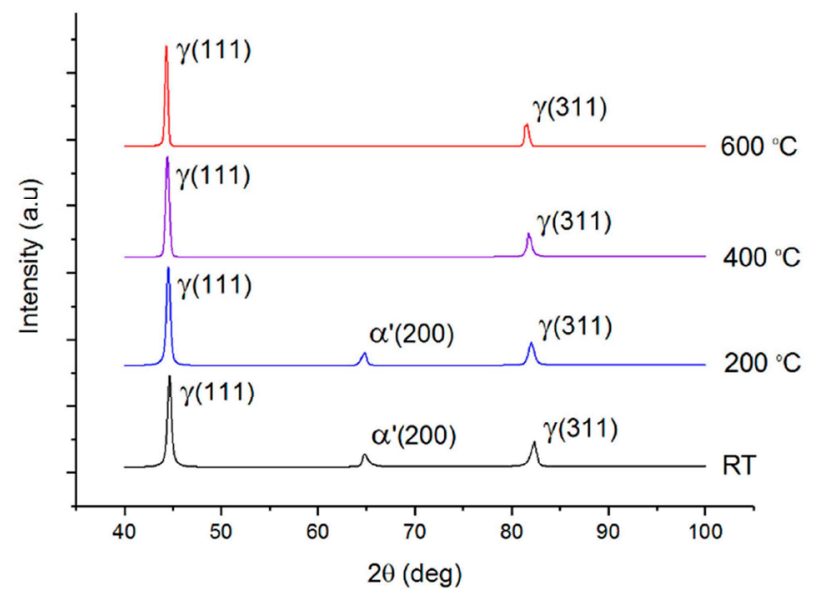

Fig 7. The result of the XRD scan, which applied $\mathrm{Cu} \mathrm{K \alpha}$ radiation with the DP980 microstructures, the $\gamma$ austenite phase and the $\alpha^{\prime}$-martensite phase

Figure 7 also clearly shows the body-centered tetragonal martensite and face-centered austenite, which comprise each separate diffracting plane. When experimenting at room temperature and $200{ }^{\circ} \mathrm{C}$, the presence of the planes can be readily observed, along with the existence of the $\alpha$-martensite phase, which appears before the deformation occurs. The material has lower formability and bending at this temperature range, which can easily cause cracking, as shown in Fig. 6. If the temperature is increased to $400{ }^{\circ} \mathrm{C}$, the martensite phase $(\alpha$ ') no longer appears. Instead, there is a prominent austenite phase $(\gamma)$ by the high stress yield, resulting in a high springback angle. According to previous literature [17], a higher martensite volume fraction was obtained with a higher work hardening, but it led to a decreased amount of springback. Therefore, the XRD result shows that the martensite phase $\left(\alpha^{\prime}\right)$ no longer appears at $400{ }^{\circ} \mathrm{C}$, resulting in springback angle increase. Increasing the temperature to $600{ }^{\circ} \mathrm{C}$ leads to an increase in ductility and results in a lack of fractures on the convex bending surface. Other authors have reported similar findings [18].
However, the findings in this study show the dominance of the austenite phase in terms of the eventual condition of the microstructure.

\section{Conclusions}

Concerning the fundamentals of the experimental study carried out and exhibited in this research, the following conclusions can be drawn:

- The amount of springback occurring in the sheet matal following the pure-bending is significantly reduced as the bending angle increases, and the amount of springback is significantly affected by temperature increased at about $400{ }^{\circ} \mathrm{C}$.

- The initial crack occurring on the convex surface of the specimen occurs significantly more slowly as the bending temperature increases.

- Intermediate heat temperature of dual phase steel resulted in a product that comprised a ferrite-plusmartensite grain structure. The lower volume fraction of $\alpha^{\prime}$-martensite declined as the temperature increased to intermediate and high levels. The quantity of austentite forms was shown to be higher than that of martensite within the DPS microstructure.

\section{References}

1. N. Pathak, C. Butcher, M.J. Worswick, E. Bellhouse, J. Gao, Materials. 10, 4(2017).

2. T. Sirinakorn, V. Uthaisanksuk, S.Srimanosaowapak, Procedia Eng. 81, (2014).

3. E. Hug, M. Martinez, J. Chottin, Mater. Sci. Eng., A. 626, (2015).

4. S. Toros, A. Polat, F. Ozturk., Mater. Des., 41, (2012).

5. N. Pornputsiri, K. Kanlayasiri, ICMM, International Conference on Mechatronics and Manufacturing (2018).

6. L. Luo, L. Wei, L. Wang, S. Zhou, X. Jin, Mater. Sci. Eng., A. 682, (2017).

7. T. Yong, L. Zhuang, J. Iron Steel Res. Int. 19, 6(2012).

8. S.M. Hussaini, S.K. Singh, A.K. Gupta, J. King Saud Univ., Eng. Sci. 26, 2(2014).

9. J. Heikkala, A. Väisänen, Proc. 11th Bienn. Conf Eng. Syst. Des. Anal, (2012).

10. M.H. Shipton and W.T. Roberts, Mat. Sci. \& Tech. 7, (1991).

11. O. Çavuşoğlu, S. Toros, H. Gürün, A. Güral, Ironmaking \& Steelmaking, (2017).

12. S. Kurukuri, A. Miroux, M. Ghosh, A.H. Boogaard, Int. J. Mater. Form. 2, (2009).

13. H. Laurent, J. Coër, P.Y. Manach, M.C. Oliveira, L.F. Menezes, Int. J. Mech. Sci. 93, (2015)

14. J. Yanagimoto, K. Oyamada, Annals CIRP. 54, (2005).

15. ASM Handbooks, 2, (2000).

16. M. Dao, M. Lie, Phil. Mag. 81, (2001).

17. H. Fathi, H.R.M. Semnani, E. Emadoddin, B.M. Sadeghi, Met. Mater. Int. 22, 406 (2016).

18. S. K. Akay, M. Yazici, A. Avinc, Proceeding of Romanian. Acd. A. 10, 1(2009). 